\title{
CREDIBLE CLAIMS RESERVES: THE BENKTANDER METHOD
}

\author{
BY \\ THOMAS MACK \\ Munich Re, Munich
}

\begin{abstract}
A BSTRACT
A claims reserving method is reviewed which was introduced by Gunnar Benktander in 1976. It is a very intuitive credibility mixture of Bornhuetter/ Ferguson and Chain Ladder. In this paper, the mean squared errors of all 3 methods are calculated and compared on the basis of a very simple stochastic model. The Benktander method is found to have almost always a smaller mean squared error than the other two methods and to be almost as precise as an exact Bayesian procedure.
\end{abstract}

\section{KEYWORDS}

Claims Reserves, Chain Ladder, Bornhuetter/Ferguson, Credibility, Standard Error

\section{INTRODUCTION}

This note on the occasion of the 80st anniversary of Gunnar Benktander focusses on a claims reserving method which was published by him in 1976 in "The Actuarial Review" of the Casualty Actuarial Society (CAS) under the title "An Approach to Credibility in Calculating IBNR for Casualty Excess Reinsurance". The Actuarial Review is the quarterly newsletter of the CAS and is normally not subscribed outside of North America. This might be the reason why Gunnar's article did not become known in Europe. Therefore, the method has been proposed a second time by the Finnish actuary Esa Hovinen in his paper "Additive and Continuous IBNR", submitted to the ASTIN Colloquium 1981 in Loen/Norway. During that colloquium, Gunnar Benktander referred to his former article and Hovinen's paper was not published further. Therefore it was not unlikely that the method was invented a third time. Indeed, Walter Neuhaus published it in 1992 in the Scandinavian Actuarial Journal under the title "Another Pragmatic Loss Reserving Method or Bornhuetter/Ferguson Revisited". He mentioned neither Benktander nor Horvinen because he did not know about 
their articles. In recent years, the method has been used occasionally in actuarial reports under the name "Iterated Bornhuetter/Ferguson Method". The present article gives a short review of the method and connects it with the name of its first publisher. Furthermore, evidence is given that the method is very useful which should already be clear from the fact that it has been invented so many times. Using a simple stochastic model it is shown that the Benktander method outperformes the Bornhuetter/Ferguson method and the chain ladder method in many situations. Moreover, simple formulae for the mean squared error of all three methods are derived. Finally, a numerical example is given and a comparison with a credibility model and a Bayesian model is made.

\section{REVIEW OF THE METHOD}

To keep notation simple we concentrate on one single accident year and on paid claims. Furthermore, we assume the payout pattern to be given, i.e. we denote with $p_{j}, 0<p_{1}<p_{2}<\ldots<p_{n}=1$, the proportion of the ultimate claims amount which is expected to be paid after $j$ years of development. After $n$ years of development, all claims are assumed to be paid. Let $U_{0}$ be the estimated ultimate claims amount, as it is expected prior to taking the own claims experience into account. For instance, $U_{0}$ can be taken from premium calculation. Then, being at the end of a fixed development year $k<n$,

$$
R_{B F}=q_{k} U_{0} \quad \text { with } \quad q_{k}=1-p_{k}
$$

is the well-known Bornhuetter/Ferguson $(B F)$ reserve (Bornhuetter/Ferguson 1972). The claims amount $C_{k}$ paid up to now does not enter the formula for $R_{B F}$, i.e. this reserving method ignores completely the current claims experience of the portfolio under consideration. Note that the axiomatic relationship between any reserve estimate $\hat{R}$ and the corresponding ultimate claims estimate $\hat{U}$ is always

$$
\hat{U}=C_{k}+\hat{R} \quad \text { and } \hat{R}=\hat{U}-C_{k}
$$

because the same relationship also holds for the true reserve $R=C_{n}-C_{k}$ and the corresponding ultimate claims $U=C_{n}$, i.e. we have

$$
U=C_{k}+R \text { and } R=U-C_{k} .
$$

For the Bornhuetter/Ferguson method this implies that the final estimate of the ultimate claims is the posterior estimate

$$
U_{B F}=C_{k}+R_{B F}
$$

whereas the prior estimate $U_{0}$ is only used to arrive at an estimate of the reserve. Note further that the payout pattern $\left\{p_{j}\right\}$ is defined by $p_{j}=E\left(C_{j}\right) / E(U)$.

Another well-known claims reserving method is the chain ladder $(C L)$ method. This method grosses up the current claims amount $C_{k}$, i.e. uses

$$
U_{C L}=C_{k} / p_{k}
$$


as estimated ultimate claims amount and

$$
R_{C L}=U_{C L}-C_{k}
$$

as claims reserve. Note that there

$$
R_{C L}=q_{k} U_{C L}
$$

holds. This reserving method considers the current claims amount $C_{k}$ to be fully credibly predictive for the future claims and ignores the prior expectation $U_{0}$ completely. One advantage of $C L$ over $B F$ is the fact that with $C L$ different actuaries come always to similar results which is not the case with $B F$ because there may be some dissent regarding $U_{0}$.

$B F$ and $C L$ represent extreme positions. Therefore Benktander (1976) proposed to replace the prior $U_{0}$ with a credibility mixture

$$
U_{c}=c U_{C L}+(1-c) U_{0} .
$$

As the credibility factor $c$ should increase similarly as the claims $C_{k}$ develop, he proposed to take $c=p_{k}$ and to estimate the claims reserve by

$$
R_{G B}=R_{B F} \cdot \frac{U_{p_{k}}}{U_{0}}
$$

This is the method as proposed by Gunnar Benktander $(G B)$. Observe that we have

$$
R_{G B}=q_{k} U_{p_{k}}
$$

and

$$
U_{p_{k}}=p_{k} U_{C L}+q_{k} U_{0}=C_{k}+R_{B F}=U_{B F}
$$

i.e.

$$
R_{G B}=q_{k} U_{B F} .
$$

This last equation means that the Benktander reserve $R_{G B}$ is obtained by applying the $B F$ procedure in an additional step to the posterior ultimate claims amount $U_{B F}$ which was arrived at by the normal $B F$ procedure. This way has been taken in some recent actuarial reports and has there been called "iterated Bornhuetter/Ferguson method".

Note again that the resulting posterior estimate

$$
U_{G B}=C_{k}+R_{G B}=\left(1-q_{k}^{2}\right) U_{C L}+q_{k}^{2} U_{0}=U_{1-q_{k}^{2}}
$$

for the ultimate claims is different from $U_{p_{k}}$ which was used as prior.

Esa Hovinen (1981) applied the credibility mixture directly to the reserves instead of the ultimates, i.e. proposed the reserve estimate

$$
R_{E H}=c R_{C L}+(1-c) R_{B F}
$$


again with $c=p_{k}$. But the Hovinen reserve

$$
R_{E H}=p_{k} q_{k} U_{C L}+\left(1-p_{k}\right) q_{k} U_{0}=q_{k} U_{p_{k}}=R_{G B}
$$

is identical to the Benktander reserve.

We have already seen that the functions $R(U)=q_{k} U$ and $U(R)=C_{k}+R$ are not inverse to each other except for $U=U_{C L}$. In addition, Table 1 shows that the further iteration of the methods of $B F$ and $G B$ for an arbitrary starting point $U_{0}$ finally leads to the chain ladder method.

We want to state this as a theorem:

Theorem 1. For an arbitrary starting point $U^{(0)}=U_{0}$, the iteration rule

$$
R^{(m)}=q_{k} U^{(m)} \quad \text { and } \quad U^{(m+1)}=C_{k}+R^{(m)}, \quad m=0,1,2, \ldots,
$$

gives credibility mixtures

$$
\begin{aligned}
& U^{(m)}=\left(1-q_{k}^{m}\right) U_{C L}+q_{k}^{m} U_{0}, \\
& R^{(m)}=\left(1-q_{k}^{m}\right) R_{C L}+q_{k}^{m} R_{B F}
\end{aligned}
$$

\begin{tabular}{|c|c|c|}
\hline Ultimate $U(R)=C_{k}+R$ & Connection & Reserve $R(U)=q_{k} U$ \\
\hline$U_{0}$ & & $R_{B F}=q_{k} U_{0}$ \\
\hline $\begin{aligned} U^{(1)} & =U_{B F}=C_{k}+R_{B F} \\
& =\left(1-q_{k}\right) U_{C L}+q_{k} U_{0}\end{aligned}$ & & $R^{(1)}=R_{G B}=q_{k} U_{B F}$ \\
\hline $\begin{aligned} U^{(2)} & =U_{G B}=C_{k}+R_{G B} \\
& =\left(1-q_{k}^{2}\right) U_{C L}+q_{k}^{2} U_{0} \\
& \ldots\end{aligned}$ & $>$ & $=\left(1-q_{k}\right) R_{C L}+q_{k} R_{B F}$ \\
\hline$U^{(m)}=\left(1-q_{k}^{m}\right) U_{C L}+q_{k}^{m} U_{0}$ & & 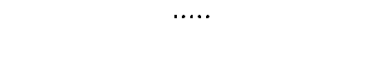 \\
\hline $\begin{aligned} U^{(m+1)} & =C_{k}+R^{(m)} \\
& =\left(1-q_{k}^{m+1}\right) U_{C L}+q_{k}^{m+1} U_{0} \\
& \ldots \ldots\end{aligned}$ & $>$ & $\begin{aligned} R^{(m)} & =q_{k} U^{(m)} \\
& =\left(1-q_{k}^{m}\right) R_{C L}+q_{k}^{m} R_{B F}\end{aligned}$ \\
\hline$U^{(\infty)}=U_{C L}$ & $\longleftrightarrow$ & $R^{(\infty)}=R_{C L}$ \\
\hline
\end{tabular}

between $B F$ and $C L$ which start at $B F$ and lead via $G B$ finally to $C L$ for $m=\infty$.

TABLE 1

ITERATION OF BORNHUETTER/FERGUSON 
Walter Neuhaus (1992) analyzed the situation in a full Bühlmann/Straub credibility framework (see section 6 for details) and compared the size of the mean squared error $m s e\left(R_{c}\right)=E\left(R_{c}-R\right)^{2}$ of

$$
R_{c}=c R_{C L}+(1-c) R_{B F}
$$

and the true reserve $R=U-C_{k}=C_{n}-C_{k}$ especially for

$$
\begin{array}{ll}
c=0 & (B F) \\
c=p_{k} & \text { (GB, called PC-predictor by Neuhaus) } \\
c=c^{*} & \text { (optimal credibility reserve) }
\end{array}
$$

where $c^{*} \in[0 ; 1]$ can be defined to be that $c$ which minimizes $m s e\left(R_{c}\right)$. Neuhaus did not include $c=1(C L)$ explicitely into his analysis.

Neuhaus showed that the mean squared error of the Benktander reserve $R_{G B}$ is almost as small as of the optimal credibility reserve $R_{c^{*}}$ except if $p_{k}$ is small and $c^{*}$ is large at the same time (cf. Figures 1 and 2 in Neuhaus (1992)). Moreover, he showed that the Benktander reserve $R_{G B}$ has a smaller mean squared error than $R_{B F}$ whenever $c^{*}>p_{k} / 2$ holds. This result is very plausible because then $c^{*}$ is closer to $c=p_{k}$ than to $c=0$.

In the following we include the $C L$ into the analysis and consider the case where $U_{0}$ is not necessarily equal to $E(U)$, i.e. consider the estimation error, too. This seems to be more realistic as in Neuhaus (1992) where $U_{0}=E(U)$ was assumed. Instead of the credibility model used by Neuhaus, we introduce a less demanding stochastic model in order to compare the precision of $R_{B F}, R_{C L}$ and $R_{G B}$. We derive a formula for the standard error of $R_{B F}$ and $R_{G B}$ (and $R_{C L}$ ) and show how the parameters required can be estimated. A numerical example is given in section 4. Moreover, there is a close connection to a paper by Gogol (1993) which will be dealt with in section 5. Finally, the connection to the credibility model is analyzed in section 6 .

\section{CALCULATION OF THE OPTIMAL CREDIBILITY FACTOR $c^{*}$ AND OF THE MEAN SQUARED ERROR OF $\boldsymbol{R}_{c}$}

In order to compare $R_{B F}, R_{C L}$ and $R_{G B}$, we use the mean squared error

$$
\operatorname{mse}\left(R_{c}\right)=E\left(R_{c}-R\right)^{2}
$$

as criterion for the precision of the reserve estimate $R_{c}$ (for a discussion see section 5). Because

$$
R_{c}=c R_{C L}+(1-c) R_{B F}=c\left(R_{C L}-R_{B F}\right)+R_{B F}
$$

is linear in $c$, the mean squared error $m s e\left(R_{c}\right)$ is a quadratic function of $c$ and will therefore have a minimum.

In the following, we consider $U_{0}$ to be an estimation function which is independent from $C_{k}, R, U$ and has expectation $E\left(U_{0}\right)=E(U)$ and variance $\operatorname{Var}\left(U_{0}\right)$. Then we have 
Theorem 2. The optimal credibility factor $c^{*}$ which minimizes the mean squared error $m s e\left(R_{c}\right)=E\left(R_{c}-R\right)^{2}$ is given by

$$
c^{*}=\frac{p_{k}}{q_{k}} \cdot \frac{\operatorname{Cov}\left(C_{k}, R\right)+p_{k} q_{k} \operatorname{Var}\left(U_{0}\right)}{\operatorname{Var}\left(C_{k}\right)+p_{k}^{2} \operatorname{Var}\left(U_{0}\right)} .
$$

Proof

$$
\begin{aligned}
E\left(R_{c}-R\right)^{2} & =E\left[c\left(R_{C L}-R_{B F}\right)+R_{B F}-R\right]^{2} \\
& =c^{2} E\left(R_{C L}-R_{B F}\right)^{2}-2 c E\left[\left(R_{C L}-R_{B F}\right)\left(R-R_{B F}\right)\right]+E\left(R_{B F}-R\right)^{2} . \\
0=\frac{\partial}{\partial c} & E\left(R_{c}-R\right)^{2}=2 c E\left(R_{C L}-R_{B F}\right)^{2}-2 E\left[\left(R_{C L}-R_{B F}\right)\left(R-R_{B F}\right)\right]
\end{aligned}
$$

yields

$$
\begin{aligned}
c^{*} & =\frac{E\left[\left(R_{C L}-R_{B F}\right)\left(R-R_{B F}\right)\right]}{E\left(R_{C L}-R_{B F}\right)^{2}}=\frac{p_{k}}{q_{k}} \cdot \frac{E\left[\left(C_{k}-p_{k} U_{0}\right)\left(R-q_{k} U_{0}\right)\right]}{E\left(C_{k}-p_{k} U_{0}\right)^{2}} \\
& =\frac{p_{k}}{q_{k}} \cdot \frac{\operatorname{Cov}\left(C_{k}-p_{k} U_{0}, R-q_{k} U_{0}\right)}{\operatorname{Var}\left(C_{k}-p_{k} U_{0}\right)}=\frac{p_{k}}{q_{k}} \cdot \frac{\operatorname{Cov}\left(C_{k}, R\right)+p_{k} q_{k} \operatorname{Var}\left(U_{0}\right)}{\operatorname{Var}\left(C_{k}\right)+p_{k}^{2} \operatorname{Var}\left(U_{0}\right)} .
\end{aligned}
$$

Here, we have used that $E\left(C_{k}\right)=p_{k} E\left(U_{0}\right)$ according to the definition of the payout pattern (and therefore $E(R)=q_{k} E\left(U_{0}\right)$ ).

Q.E.D.

In order to estimate $c^{*}$, we need a model for $\operatorname{Var}\left(C_{k}\right)$ and $\operatorname{Cov}\left(C_{k}, R\right)$. The following model is not more than a slightly refined definition of the payout pattern:

$$
\begin{aligned}
& E\left(C_{k} / U \mid U\right)=p_{k}, \\
& \operatorname{Var}\left(C_{k} / U \mid U\right)=p_{k} q_{k} \beta^{2}(U) .
\end{aligned}
$$

The factor $q_{k}$ in (3) is necessary in order to secure that $\operatorname{Var}\left(C_{k} \mid U\right) \rightarrow 0$ as $k$ approaches $n$. A similar argument holds for $p_{k}$ in case of very small values. A parametric example is obtained if the ratio $C_{k} / U$, given $U$, has a $\operatorname{Beta}\left(a p_{k}, a q_{k}\right)$-distribution with $a>0$; in this case $\beta^{2}(U)=(a+1)^{-1}$. Thus, in the simple cases, $\beta^{2}(U)$ depends neither on $U$ nor on $k$. If the variability of $C_{k} / U$ for high values of $U$ is higher, then $\beta^{2}(U)=\left(U / U_{0}\right) \cdot \beta^{2}$ is a reasonable assumption.

From assumptions (2) and (3) and with $\alpha^{2}(U):=U^{2} \beta^{2}(U)$ we gather

$$
\begin{aligned}
& E\left(C_{k} \mid U\right)=p_{k} U, \\
& \operatorname{Var}\left(C_{k} \mid U\right)=p_{k} q_{k} \alpha^{2}(U), \\
& \begin{aligned}
E\left(C_{k}\right)=p_{k} E(U), \\
\operatorname{Var}\left(C_{k}\right)=p_{k} q_{k} E\left(\alpha^{2}(U)\right)+p_{k}^{2} \operatorname{Var}(U) \\
\quad=p_{k} E\left(\alpha^{2}(U)\right)+p_{k}^{2}\left(\operatorname{Var}(U)-E\left(\alpha^{2}(U)\right)\right),
\end{aligned}
\end{aligned}
$$




$$
\begin{aligned}
& \operatorname{Cov}\left(C_{k}, U\right)=\operatorname{Cov}\left(E\left(C_{k} \mid U\right), U\right)=p_{k} \operatorname{Var}(U), \\
& \operatorname{Cov}\left(C_{k}, R\right)=\operatorname{Cov}\left(C_{k}, U\right)-\operatorname{Var}\left(C_{k}\right)=p_{k} q_{k}\left(\operatorname{Var}(U)-E\left(\alpha^{2}(U)\right)\right), \\
& E(R)=E(U)-E\left(C_{k}\right)=q_{k} E(U), \\
& \operatorname{Var}(R)=\operatorname{Var}(U)-2 \operatorname{Cov}\left(C_{k}, U\right)+\operatorname{Var}\left(C_{k}\right) \\
& =\operatorname{Var}(U)\left(1-2 p_{k}+p_{k}^{2}\right)+p_{k} q_{k} E\left(\alpha^{2}(U)\right) \\
& =q_{k}^{2} \operatorname{Var}(U)+p_{k} q_{k} E\left(\alpha^{2}(U)\right) \\
& =q_{k} E\left(\alpha^{2}(U)\right)+q_{k}^{2}\left(\operatorname{Var}(U)-E\left(\alpha^{2}(U)\right)\right) .
\end{aligned}
$$

By inserting (4) and (5) into (1), we immediately obtain

Theorem 3. Under the assumptions of model (2)-(3), the optimal credibility factor $c^{*}$ which minimizes $m s e\left(R_{c}\right)$ is given by

$$
c^{*}=\frac{p_{k}}{p_{k}+t} \quad \text { with } \quad t=\frac{E\left(\alpha^{2}(U)\right)}{\operatorname{Var}\left(U_{0}\right)+\operatorname{Var}(U)-E\left(\alpha^{2}(U)\right)} .
$$

Some further straightforward calculations lead to

Theorem 4. Under the assumptions of model (2)-(3), we have the following formulae for the mean squared error:

$$
\begin{aligned}
\operatorname{mse}\left(R_{B F}\right) & =E\left(\alpha^{2}(U)\right) q_{k}\left(1+q_{k} / t\right), \\
m s e\left(R_{C L}\right) & =E\left(\alpha^{2}(U)\right) q_{k} / p_{k}, \\
\operatorname{mse}\left(R_{c}\right) & =E\left(\alpha^{2}(U)\right)\left(\frac{c^{2}}{p_{k}}+\frac{1}{q_{k}}+\frac{(1-c)^{2}}{t}\right) q_{k}^{2} .
\end{aligned}
$$

\section{Proof}

$$
\begin{aligned}
m s e\left(R_{B F}\right) & =E\left(R_{B F}-R\right)^{2}=\operatorname{Var}\left(R_{B F}-R\right)=\operatorname{Var}\left(R_{B F}\right)+\operatorname{Var}(R) \\
& =q_{k}^{2} \operatorname{Var}\left(U_{0}\right)+q_{k}^{2}\left(\operatorname{Var}(U)-E\left(\alpha^{2}(U)\right)\right)+q_{k} E\left(\alpha^{2}(U)\right) \\
& =E\left(\alpha^{2}(U)\right)\left(q_{k}+q_{k}^{2} / t\right), \\
m s e\left(R_{C L}\right) & =E\left(R_{C L}-R\right)^{2}=\operatorname{Var}\left(R_{C L}-R\right) \\
& =\operatorname{Var}\left(R_{C L}\right)-2 \operatorname{Cov}\left(R_{C L}, R\right)+\operatorname{Var}(R) \\
& =q_{k}^{2} \operatorname{Var}\left(C_{k}\right) / p_{k}^{2}-2 q_{k} \operatorname{Cov}\left(C_{k}, R\right) / p_{k}+\operatorname{Var}(R) \\
& =E\left(\alpha^{2}(U)\right) q_{k} / p_{k}, \\
m s e\left(R_{c}\right) & =E\left(c R_{C L}+(1-c) R_{B F}-R\right)^{2} \\
& =E\left[c\left(R_{C L}-R\right)+(1-c)\left(R_{B F}-R\right)\right]^{2} \\
& =c^{2} m s e\left(R_{C L}\right)+2 c(1-c) E\left[\left(R_{C L}-R\right)\left(R_{B F}-R\right)\right]+(1-c)^{2} m s e\left(R_{B F}\right),
\end{aligned}
$$




$$
\begin{aligned}
E\left[\left(R_{C L}-R\right)\left(R_{B F}-R\right)\right] & =\operatorname{Cov}\left(R_{C L}-R, R_{B F}-R\right) \\
& =-\operatorname{Cov}\left(R_{C L}, R\right)+\operatorname{Var}(R) \\
& =\operatorname{Var}(R)-q_{k} \operatorname{Cov}\left(C_{k}, R\right) / p_{k} \\
& =q_{k} E\left(\alpha^{2}(U)\right) .
\end{aligned}
$$

and putting all pieces together leads to the formula stated.

Q.E.D.

An actuary who is able to assess $p_{k}=E\left(C_{k} / U \mid U\right)$ and $U_{0}$ (i.e. $E\left(U_{0}\right)$ ) should also be able to estimate $\operatorname{Var}\left(U_{0}\right)$ and $\operatorname{Var}\left(C_{k} / U \mid U\right)$ or $E\left(\operatorname{Var}\left(C_{k} \mid U\right)\right)$ as well as $\operatorname{Var}(U)$. Therefrom, he can deduce $E\left(\alpha^{2}(U)\right)=E\left(\operatorname{Var}\left(C_{k} \mid U\right)\right) /\left(p_{k} q_{k}\right)-$ or $E\left(\alpha^{2}(U)\right)=\operatorname{Var}\left(C_{k} / U \mid U\right) E\left(U^{2}\right) /\left(p_{k} q_{k}\right)$ if $\operatorname{Var}\left(C_{k} / U \mid U\right)$ does not depend on $U$ - and finally the parameter $t$. Then he has now a formula for the mean squared error of the $B F$ method and a very simple formula for the $C L$ method (where $t$ is not needed) and can calculate the best estimate $R_{c^{*}}$ including its mean squared error as well as the one of $R_{G B}$.

Regarding the very simple formula for $m s e\left(R_{C L}\right)$ we should note that this formula deviates from the corresponding one (i.e. for the unconditional mean squared error with known payout pattern) of the distribution-free chain ladder model of Mack (1993). The reason is that the models underlying are slightly different: Here we have

$$
E\left(\frac{C_{k}}{U} \mid U\right)=p_{k}
$$

and the model of Mack (1993) can be written as

$$
E\left(\frac{U}{C_{k}} \mid C_{k}\right)=\frac{1}{p_{k}}
$$

Using theorem 4, we now compare the mean squared errors of the different methods in terms of $p_{k}$ and $t$. First, we have

$$
\operatorname{mse}\left(R_{B F}\right)<\operatorname{mse}\left(R_{C L}\right) \Longleftrightarrow p_{k}<t,
$$

i.e. we should use $B F$ for the green years $\left(p_{k}<t\right)$ and $C L$ for the rather mature years $\left(p_{k}>t\right)$. This is very plausible and the author is aware that some companies use this rule with $t=0.5$. But the volatility measure $t$ varies from one business to the other and therefore the actuary should try to estimate $t$ in every single case as is shown in the next section.

Furthermore, we have

$$
\begin{aligned}
& \operatorname{mse}\left(R_{G B}\right)<\operatorname{mse}\left(R_{B F}\right) \quad \Longleftrightarrow t<2-p_{k}, \\
& \operatorname{mse}\left(R_{G B}\right)<\operatorname{mse}\left(R_{C L}\right) \quad \Longleftrightarrow t>p_{k} q_{k} /\left(1+p_{k}\right),
\end{aligned}
$$

i.e. $G B$ is better than $B F$ except $t$ is very large and is better than $C L$ except $t$ is very small, see Figure 1 where for each of the three areas it is indicated which of $B F, G B, C L$ is best. In the numerical example below, it will become clear that $t$ is almost always in the $G B$ area. 


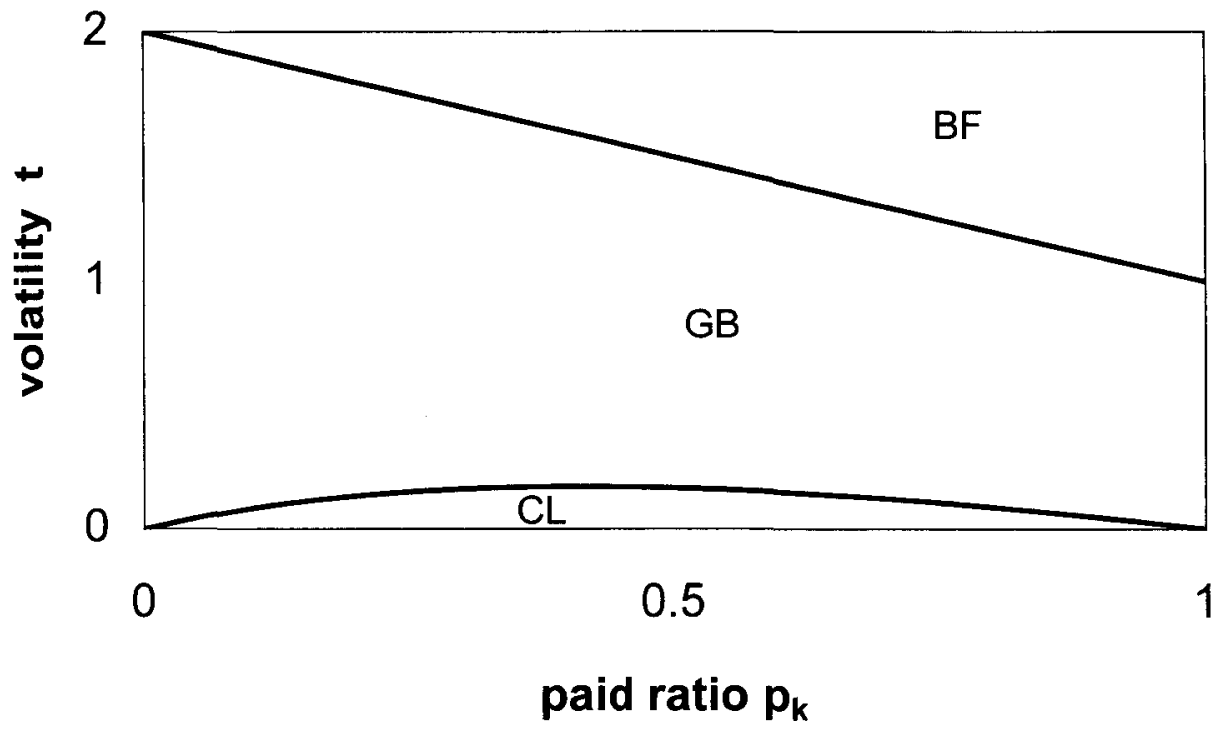

Figure 1: Areas of smallest mean squared error.

\section{NUMERICAL EXAMPLE}

Assume that the a priori expected ultimate claims ratio is $90 \%$ of the premium, i.e. $U_{0}=90 \%$. Assuming further $p_{k}=0.50$ for $k=3$, we have $R_{B F}=45 \%$ (all $\%$ ages relate to the premium). Let the paid claims ratio be $C_{k}=55 \%$, then $U_{C L}=110 \%$ and $R_{C L}=55 \%$. Taken together, we have $R_{G B}=50 \%$.

In order to calculate the standard errors, we have to assess $\operatorname{Var}(U), \operatorname{Var}\left(U_{0}\right)$ and $E\left(\alpha^{2}(U)\right)$. For $\operatorname{Var}(U)$, we can use a consideration of the following type: We assume that the ultimate claims ratio will never be below $60 \%$ and only once every 20 years above $150 \%$. Then, assuming a shifted lognormal distribution with expectation $90 \%$, we get $\operatorname{Var}(U)=(35 \%)^{2}$. This rather high variance is typical for a reinsurance business or a small direct portfolio.

Regarding $E\left(\alpha^{2}(U)\right)$, we consider here the special case where $\beta^{2}(U)=\beta^{2}$ does not depend on $U$ (e.g. using a Beta distribution), i.e. $E\left(\alpha^{2}(U)\right)=E\left(U^{2}\right) \beta^{2}=E\left(U^{2}\right) \operatorname{Var}\left(C_{k} / U \mid U\right) /\left(p_{k} q_{k}\right)$. Therefore, we have to assess $\operatorname{Var}\left(C_{k} / U \mid U\right)$, i.e. the variability of the payment ratio $C_{k} / U$ around its mean $p_{k}$. If we assume - e.g. by looking at the ratios $C_{k} / U$ of past accident years - that $C_{k} / U$ will be almost always between 0.30 and 0.70 , then using the two-sigma rule from the normal distribution - we have a standard deviation of 0.10 , i.e. $\operatorname{Var}\left(C_{k} / U \mid U\right)=0.10^{2}$, which leads to $\beta^{2}=\operatorname{Var}\left(C_{k} / U \mid U\right) /\left(p_{k} q_{k}\right)=0.20^{2}$ and $E\left(\alpha^{2}(U)\right)=E\left(U^{2}\right) \beta^{2}=0.193^{2}$.

Finally, the most difficult task is to assess $\operatorname{Var}\left(U_{0}\right)$ but this has much less influence on $t$ than $\operatorname{Var}(U)$ (which is always larger) and $E\left(\alpha^{2}(U)\right)$. Moreover, an actuary who is able to establish a point estimate $U_{0}$ should also be able to estimate the uncertainty $\operatorname{Var}\left(U_{0}\right)$ of his point estimate. Thus, there will be a 
certain interval or range of values where the actuary takes his choice of $U_{0}$ from. Then he can take this interval and use the two-sigma rule to produce the standard deviation $\sqrt{\operatorname{Var}\left(U_{0}\right)}$. Let us assume that in our example $\operatorname{Var}\left(U_{0}\right)=(15 \%)^{2}$.

Now we can calculate $t=0.346$ and all standard errors ( $=$ square root of the estimated mean squared error) as well as the optimal credibility reserve $R_{c^{*}}$ :

$$
\begin{aligned}
R_{B F} & =45 \% \pm 21.3 \% \\
R_{C L} & =55 \% \pm 19.3 \% \\
R_{G B} & =50 \% \pm 17.3 \% \\
R_{C^{*}} & =50.9 \% \pm 17.2 \% \quad \text { with } \quad c^{*}=0.591 .
\end{aligned}
$$

Note that these standard errors are based on the unconditional mean squared error (cf. discussion in the next section) and on a known pattern $\left\{p_{j}\right\}$. Including the uncertainty of the $p_{j}$ will increase the standard error.

For the purpose of comparison, we look at a more stable business, too: Assume that $\operatorname{Var}(U)=(10 \%)^{2}, \operatorname{Var}\left(U_{0}\right)=(5 \%)^{2}$ and $\operatorname{Var}\left(C_{k} / U \mid U\right)=(0.03)^{2}$. Then, everything else being equal, we obtain $\beta^{2}=0.06^{2}, E\left(\alpha^{2}(U)\right)=0.054^{2}$, $t=0.309$ and

$$
\begin{aligned}
R_{B F} & =45 \% \pm 6.2 \% \\
R_{C L} & =55 \% \pm 5.4 \% \\
R_{G B} & =50 \% \pm 4.9 \% \\
R_{C^{*}} & =51.2 \% \pm 4.9 \% \quad \text { with } \quad c^{*}=0.618
\end{aligned}
$$

In both cases, $G B$ has a smaller mean squared error than $B F$ and $C L$, and the size of $t$ has not changed much, because the relative sizes of the three variances $\operatorname{Var}(U), \operatorname{Var}\left(U_{0}\right), \operatorname{Var}\left(C_{k} / U \mid U\right)$ are similar. A closer look at formula (6) shows that the size of $t$ is changed more if $E\left(\alpha^{2}(U)\right)$ (i.e. $\operatorname{Var}\left(C_{k} / U \mid U\right)$ ) is changed than if $\operatorname{Var}(U)$ or $\operatorname{Var}\left(U_{0}\right)$ are changed. In the first example, for instance, we had $\operatorname{Var}\left(C_{k} / U \mid U\right)=0.10^{2}$ and $G B$ was better than $C L$ and $B F$. If we change the variability of the paid ratio to $\operatorname{Var}\left(C_{k} / U \mid U\right) \geq 0.153^{2}$, then $t \geq 1.51$ and $B F$ is better than $G B$ and $C L$. If we change it to $\operatorname{Var}\left(C_{k} / U \mid U\right) \leq 0.074^{2}$, then $t \leq 0.164$ and $C L$ is better than $G B$ and $B F$, see Figure 1. But in the large range of normal values of $\operatorname{Var}\left(C_{k} / U \mid U\right), G B$ is better than $C L$ and $B F$. Because $\operatorname{Var}\left(U_{0}\right)$ is always smaller than $\operatorname{Var}(U)$, the size of $t$ is essentially determined by the ratio $\operatorname{Var}\left(C_{k} / U \mid U\right) / \operatorname{Var}(U)$. 


\section{APPLICATION OF AN EXACT BAyESIAN MODEL TO THE NUMERICAL EXAMPLE}

If we make distributional assumptions for $U$ and $C_{k} \mid U$, we can determine the exact distribution of $U \mid C_{k}$ according to Bayes' theorem. This was done by Gogol (1993) who assumed that $U$ and $C_{k} \mid U$ have lognormal distributions because then $U \mid C_{k}$ has a lognormal distribution, too.

Applied to our first numerical example, this model is:

$$
\begin{aligned}
& U \sim \text { Lognormal }\left(\mu, \sigma^{2}\right) \quad \text { with } E(U)=90 \%, \operatorname{Var}(U)=(35 \%)^{2}, \\
& C_{k} \mid U \sim \operatorname{Lognormal}\left(\nu, \tau^{2}\right) \quad \text { with } \quad E\left(C_{k} \mid U\right)=p_{k} U, \operatorname{Var}\left(C_{k} \mid U\right)=p_{k} q_{k} \beta^{2} U^{2}
\end{aligned}
$$

where $\beta^{2}=0.20^{2}$ is as before, i.e. such that $\operatorname{Var}\left(C_{k} / U \mid U\right)=0.10^{2}$.

This yields

$$
\begin{aligned}
\sigma^{2} & =\ln \left(1+\operatorname{Var}(U) /(E(U))^{2}\right)=0.375^{2}, \\
\mu & =\ln (E(U))-\sigma^{2} / 2=-0.176, \\
\tau^{2} & =\ln \left(1+\beta^{2} q_{k} / p_{k}\right)=0.198^{2} .
\end{aligned}
$$

Then (see Gogol (1993)),

$$
U \mid C_{k} \sim \text { Lognormal }\left(\mu_{1}, \sigma_{1}^{2}\right)
$$

with

$$
\begin{aligned}
\mu_{1} & =z\left(\tau^{2}+\ln \left(C_{k} / p_{k}\right)\right)+(1-z) \mu=0.067 \\
\sigma_{1}^{2} & =z \tau^{2}=0.175^{2} \\
z & =\sigma^{2} /\left(\sigma^{2}+\tau^{2}\right)=0.782
\end{aligned}
$$

This yields (at $C_{k}=55 \%$ )

$$
\begin{aligned}
& E\left(U \mid C_{k}\right)=\exp \left(\mu_{1}+\sigma_{1}^{2} / 2\right)=108.6 \%, \\
& E\left(R \mid C_{k}\right)=E\left(U \mid C_{k}\right)-C_{k}=53.6 \%, \\
& \operatorname{Var}\left(R \mid C_{k}\right)=\operatorname{Var}\left(U \mid C_{k}\right)=\left(E\left(U \mid C_{k}\right)\right)^{2}\left(\exp \left(\sigma_{1}^{2}\right)-1\right)=(19.2 \%)^{2} .
\end{aligned}
$$

If we compare this last result with the mean squared errors obtained in section 4 , we should recall that $E\left(R \mid C_{k}\right)$ minimizes the conditional mean squared error

$$
E\left((\hat{R}-R)^{2} \mid C_{k}\right)=\operatorname{Var}\left(R \mid C_{k}\right)+\left(\hat{R}-E\left(R \mid C_{k}\right)\right)^{2}
$$

among all estimators $\hat{R}$ which are a square integrable function of $C_{k}$ as well as it minimizes the unconditional mean squared error

$$
E(\hat{R}-R)^{2}=E\left(\operatorname{Var}\left(R \mid C_{k}\right)\right)+E\left(\hat{R}-E\left(R \mid C_{k}\right)\right)^{2}
$$

because the first term of the r.h.s. does not depend on $\hat{R}$. But the resulting minimum values $\operatorname{Var}\left(R \mid C_{k}\right)$ and $E\left(\operatorname{Var}\left(R \mid C_{k}\right)\right)$ are different. 
Basically, in claims reserving we should minimize the conditional mean squared error, given $C_{k}$, because we are only interested in the future variability and because $C_{k}$ remains a fixed part of the ultimate claims $U$. But if $E\left(R \mid C_{k}\right)$ is a linear function of $C_{k}$ (like $R_{c}$ ), this function can be found by minimizing the unconditional (average) mean squared error. Moreover, the latter can often be calculated easier than the conditional mean squared error as it is the case in model (2)-(3). The unconditional mean squared error is the appropriate measure to compare the precision of different reserving methods.

Altogether, it is clear that the mean squared errors calculated in section 4 are average (unconditional) mean squared errors, averaged over all possible values of $C_{k}$. Therefore, in order to make a fair comparison of the various methods in our numerical example, we must calculate the unconditional mean squared error $E\left(\operatorname{Var}\left(R \mid C_{k}\right)\right)$ in the Bayesian model, too.

For this purpose, we have to integrate $\operatorname{Var}\left(R \mid C_{k}\right)$ over $C_{k}$ and therefore need the distribution of $C_{k}$ which we obtain by mixing the distributions of $C_{k} \mid U$ and $U$ :

$$
\begin{aligned}
& C_{k} / p_{k} \sim \text { Lognormal }\left(\mu-\tau^{2} / 2, \sigma^{2}+\tau^{2}\right), \\
& \exp \left(2 z \ln \left(C_{k} / p_{k}\right)\right) \sim \text { Lognormal }\left(2 z \mu-z \tau^{2}, 4 z^{2}\left(\sigma^{2}+\tau^{2}\right)\right) .
\end{aligned}
$$

This yields

$$
\begin{aligned}
E\left(\operatorname{Var}\left(R \mid C_{k}\right)\right) & =E\left(\exp \left(2 \mu_{1}+\sigma_{1}^{2}\right)\left(\exp \left(\sigma_{1}^{2}\right)-1\right)\right) \\
& =E\left(\exp \left(2 z \ln \left(C_{k} / p_{k}\right)\right)\right) \exp \left(3 z \tau^{2}+2(1-z) \mu\right)\left(\exp \left(z \tau^{2}\right)-1\right) \\
& =\exp \left(2 \mu+2 \sigma^{2}\right)\left(\exp \left(z \tau^{2}\right)-1\right) \\
& =(17.0 \%)^{2} .
\end{aligned}
$$

This shows finally, that the exact Bayesian model on average has only a slightly smaller mean squared error than the optimal credibility reserve $R_{c^{*}}$ and the Benktander reserve $R_{G B}$. But if we recall that, with the exact Bayesian procedure, we assume to exactly know the distributional laws without any estimation error, then the slight improvement in the mean squared error does not pay for the strong assumptions made.

\section{CONNECTION TO THE CREDIBILITY MODEL}

Finally, we establish an interesting connection between the model (2)-(3) and the credibility model used in Neuhaus (1992). There, the Bühlmann/Straub credibility model was applied to the incremental losses and payouts: For $j=1, \ldots, n$ (where $n$ is such that $p_{n}=1$ ) let

$$
m_{j}=p_{j}-p_{j-1}
$$


be the incremental payout pattern and

$$
S_{j}=C_{j}-C_{j-1}
$$

be the incremental claims (with the convention $p_{0}=0$ and $C_{0}=0$ ). Then the Bühlmann/Straub credibility model makes the following assumptions:

$$
\begin{array}{cc}
S_{1}\left|\Theta, \ldots, S_{n}\right| \Theta \quad \text { are independent, } \\
E\left(S_{j} / m_{j} \mid \Theta\right)=\mu(\Theta), & 1 \leq j \leq n, \\
\operatorname{Var}\left(S_{j} / m_{j} \mid \Theta\right)=\sigma^{2}(\Theta) / m_{j} & 1 \leq j \leq n,
\end{array}
$$

where $\Theta$ is the unknown distribution quality of the accident year. Assumption (7) can be crucial in practise. Model (7)-(9) can be set up without refering to $p_{j}$ by just requiring $m_{j}>0$ and $m_{1}+\ldots+m_{n}=1$. Then the following formulae still hold using $p_{k}:=m_{1}+\ldots+m_{k}$.

From (7)-(9) we obtain

$$
\begin{aligned}
& E\left(C_{k} \mid \Theta\right)=p_{k} \mu(\Theta), \\
& \operatorname{Var}\left(C_{k} \mid \Theta\right)=p_{k} \sigma^{2}(\Theta) .
\end{aligned}
$$

The latter formula shows, that the credibility model is different from model (2)-(3) where we have $\operatorname{Var}\left(C_{k} \mid U\right)=p_{k} q_{k} \alpha^{2}(U)$, i.e. we do not have $\Theta=U$.

In the credibility model (7)-(9) we obtain further

$$
\begin{aligned}
& E\left(C_{k}\right)=p_{k} E(\mu(\Theta))=p_{k} E\left(C_{n}\right)=p_{k} E(U), \\
& \operatorname{Var}\left(C_{k}\right)=p_{k} E\left(\sigma^{2}(\Theta)\right)+p_{k}^{2} \operatorname{Var}(\mu(\Theta)), \\
& \begin{aligned}
\operatorname{Cov}\left(C_{k}, U\right)=E\left(\operatorname{Cov}\left(C_{k}, C_{k} \mid \Theta\right)\right)+\operatorname{Cov}\left(p_{k} \mu(\Theta), \mu(\Theta)\right) \\
\quad=p_{k}\left(E\left(\sigma^{2}(\Theta)\right)+\operatorname{Var}(\mu(\Theta))\right),
\end{aligned} \\
& \begin{array}{l}
\operatorname{Cov}\left(C_{k}, R\right)=p_{k} q_{k} \operatorname{Var}(\mu(\Theta)), \\
E(R)=q_{k} E(\mu(\Theta))=q_{k} E(U), \\
\operatorname{Var}(R)=q_{k} E\left(\sigma^{2}(\Theta)\right)+q_{k}^{2} \operatorname{Var}(\mu(\Theta)) .
\end{array}
\end{aligned}
$$

If we compare these formulae with the corresponding formulae of model (2)-(3) and take into account that here

$$
\operatorname{Var}(\mu(\Theta))=\operatorname{Var}(U)-E\left(\sigma^{2}(\Theta)\right)
$$

holds (from (10) with $k=n$ ), then we see that these formulae are completely identical if $E\left(\alpha^{2}(U)\right)=E\left(\sigma^{2}(\Theta)\right)$. This leads immediately to

Theorem 5. The formulae of theorems 3 and 4 hold for model (7)-(9), too, after having replaced $E\left(\alpha^{2}(U)\right)$ with $E\left(\sigma^{2}(\Theta)\right)$. 
In the credibility model, a natural estimate of $E\left(\sigma^{2}(\Theta)\right)$ can be established: From

$$
\operatorname{Var}\left(S_{j} / m_{j} \mid \Theta\right)=\sigma^{2}(\Theta) / m_{j}
$$

and

$$
\sum_{j=1}^{k} m_{j} \frac{S_{j}}{m_{j}} / \sum_{j=1}^{k} m_{j}=C_{k} / p_{k}=U_{C L}
$$

it follows that

$$
\sigma^{2}=\frac{1}{k-1} \sum_{j=1}^{k} m_{j}\left(\frac{S_{j}}{m_{j}}-U_{C L}\right)^{2}
$$

is an unbiased estimator of $E\left(\sigma^{2}(\Theta)\right)$. We can write

$$
\sigma^{2}=p_{k} s^{2} /(k-1)
$$

where

$$
s^{2}=\sum_{j=1}^{k} m_{j}\left(\frac{S_{j}}{m_{j}}-U_{C L}\right)^{2} / \sum_{j=1}^{k} m_{j}
$$

can be calculated easily as the $m_{j}$-weighted average of the squared deviations of the observed ratios $S_{j} / m_{j}$ from their weighted mean $U_{C L}$. Note that each $S_{j} / m_{j}$ is an unbiased estimate of the expected ultimate claims $E(U)$.

If in our numerical example in addition to $p_{3}=0.50$ and $C_{3}=55 \%$ we have $p_{1}=0.10, \quad p_{2}=0.30, \quad C_{1}=15 \%, \quad C_{2}=27 \%, \quad$ then $m_{1}=0.10, \quad m_{2}=0.20$, $m_{3}=0.20, \quad S_{1}=15 \%, S_{2}=12 \%, S_{3}=28 \%$, and the ratios $S_{1} / m_{1}=1.5$, $S_{2} / m_{2}=0.6, S_{3} / m_{3}=1.4$ have a variance $s^{2}=0.41^{2}$. Then the estimate for $E\left(\sigma^{2}(\Theta)\right)$ is $\sigma^{2}=0.205^{2}$. With $C_{1}=10 \%$ and $C_{2}=30 \%$ we would get $\sigma^{2}=0.061^{2}$ indicating a more stable case.

Note that for the estimation of $E\left(\alpha^{2}(U)\right)$ the observation of several accident years is necessary. Anyhow, model (2)-(3) is less demanding than model (7)-(9).

\section{CONCLUSION}

In claims reserving, the actuary has usually two independent estimators $R_{B F}$ and $R_{C L}$, at his disposal: One is based on prior knowledge $\left(U_{0}\right)$, the other is based on the claims already paid $\left(C_{k}\right)$. It is a well-known lemma of Statistics that from several independent and unbiased estimators one can form a better estimator (i.e. with smaller variance) by putting them together via a linear combination. From this general perspective, too, it is clear that the $G B$ reserve should be superior to $B F$ or $C L$.

More precisely, the foregoing analysis has shown that $G B$ has a smaller mean squared error than $B F$ and $C L$ if the payout pattern is neither extremely volatile 
nor extremely stable. This conclusion is derived within a model whose assumptions are nothing more than a precise definition of the term 'payout pattern'. Therefore, actuaries should include the Benktander method in their standard reserving methods.

Finally, we want to emphasize that all formulae derived rely on the assumption that the prior estimate $U_{0}$ and the observed claims $C_{k}$ are independent. This means that these formulae probably will not hold any more for a 'prior' $U_{0}$ which has been adjusted during the development period as it is often done in practise. Such an adjustment is like choosing an $U_{c}$ with an unknown $c$ and gives a procedure which is much less objective than the Benktander method.

\section{ACKNOWLEDGEMENT}

This paper has benefitted from the discussions at and after the RESTIN meeting 1999, especially with Ole Hesselager.

\section{REFERENCES}

Benktander, G. (1976) An Approach to Credibility in Calculating IBNR for Casualty Excess Reinsurance. In The Actuarial Review, April 1976, p. 7.

BornhUetTer, R.L. and FERguson, R.E. (1972) The Actuary and IBNR. In Proceedings of the Casualty Actuarial Society, Vol. LIX, 181-195.

Gogol, D. (1993) Using Expected Loss Ratios in Reserving. In Insurance: Mathematics and Economics 12, 297-299.

Hovinen, E. (1981) Additive and Continuous IBNR. ASTIN Colloquium Loen/Norway.

MACK, Th. (1993) Distribution-free Calculation of the Standard Error of Chain Ladder Reserve Estimates. ASTIN Bulletin 23 (1993), 213-225.

Neuhaus, W. (1992) Another Pragmatic Loss Reserving Method or Bornhuetter/Ferguson Revisited. In Scand. Actuarial J. 1992, 151-162.

DR. THOMAS MACK

Munich Re

80791 München

Germany

E-mail: tmack(a)munichre.com 